\title{
MITOCHONDRIAL DNA COPY NUMBER IS ASSOCIATED WITH ATTENTION DEFICIT HYPERACTIVITY DISORDER
}

\author{
Hakan Öğütlü ${ }^{1}$ İbrahim Selçuk Esin ${ }^{2}$, Haktan Bağış Erdem ${ }^{3}$, \\ Abdülgani Tatar ${ }^{4} \&$ Onur Burak Dursun ${ }^{5}$ \\ ${ }^{1}$ Department of Child and Adolescent Psychiatry, Ankara City Hospital, Ankara, Turkey \\ ${ }^{2}$ Department of Child and Adolescent Psychiatry, Ataturk University Faculty of Medicine, Erzurum, Turkey \\ ${ }^{3}$ Department of Medical Genetic, Dr. Abdurrahman Yurtaslan Ankara Oncology Training and Research Hospital, \\ Ankara, Turkey \\ ${ }^{4}$ Department of Medical Genetic, Ataturk University Faculty of Medicine, Erzurum, Turkey \\ ${ }^{5}$ Department of Child and Adolescent Psychiatry, University of Health Sciences Faculty of Medicine, Trabzon, Turkey
}

received: $13.8 .2019 ; \quad$ revised: $28.1 .2020 ; \quad$ accepted: 23.3 .2020

\section{SUMMARY}

Background: Attention deficit hyperactivity disorder (ADHD) is the most common psychiatric disorder in children. Several hypotheses have been proposed to explain its etiology. Mitochondrial dysfunction (MD) is suggested to be one of the causes of Attention Deficit Hyperactivity Disorder. The objective of the study was to evaluate the relationship between MD and ADHD by investigating mitochondrial DNA (mtDNA) levels from peripheral blood leukocytes, one of the best biomarkers of mitochondrial dysfunction.

Subjects and methods: This study included 56 children aged 6-16 years who were diagnosed with ADHD for the first time and 56 age- and sex-matched children without ADHD. Real-time PCR was performed to determine the relative mtDNA copy number in each study participant.

Results: The mean mtDNA copy number of the case group was $57.623 \pm 24.827$ and that of the control group was $44.204 \pm 18.926$ $(p=0.002)$. The mtDNA copy number of the case group was higher than that of the control group. Results of ROC curve analysis provided a mtDNA cutoff value of 45 .

Conclusion: Significantly higher mtDNA copy number in ADHD group may suggest mitochondrial dysfunction in the etiopathogenesis of ADHD.

Key words: attention deficit hyperactivity disorder - ADHD - mitochondrial dysfunction - mtDNA - oxidative stress

\section{INTRODUCTION}

Attention deficit hyperactivity disorder (ADHD) is a developmental neuropsychiatric disorder characterized by inattention, hyperactivity, and impulsivity, which begins during early childhood and continues throughout the lifetime of the affected individual (APA 2013, Polanczyk et al. 2007).

Several hypotheses have been proposed to explain the etiology of ADHD. Oxidative stress is suggested to be one of the causes of ADHD and has garnered considerable attention in recent years. Normal oxidationreduction reactions occurring during cellular metabolism lead to the formation of toxic metabolites called reactive oxygen species (ROS). Organisms produce antioxidants to counteract the harmful effects of the ROS. Oxidative stress occurs when the proportion of antioxidants produced is not sufficient to counteract the harmful effects of ROS (Valko et al. 2006). Oxidative stress damages cellular proteins, lipids, carbohydrates, and nucleic acids (Filomeni \& Ciriolo 2006). The brain tissue is highly susceptible to the harmful effects of oxidative stress induced by free radicals because of the moderate levels of antioxidants in the brain despite its high energy requirement (Kim et al. 2015). Various studies have shown that levels of total oxidant stress (TOS) (Selek et al. 2012); pseudocholinesterase (Archana et al. 2012); nitric oxide synthase, adenosine deaminase, and xanthine oxidase (Ceylan et al. 2012); and nitric oxide and malondialdehyde (Ceylan et al. 2010) are higher in patients with ADHD than in control subjects.

Despite these evidences highlighting the potential role of ROS in ADHD development, mechanisms underlying the contribution of oxidative stress in the pathogenesis of ADHD at the cellular level is unclear. Mitochondria, particularly mitochondrial DNA (mtDNA), which is considered as a potential biomarker of mitochondrial dysfunction (MD) (Malik \& Czajka 2013), is highly susceptible to the harmful effects of ROS. MD is suggested to be the most likely mechanism through which oxidative stress contributes to the pathogenesis of ADHD (Burçak \& Andican 2004, Eşrefoğlu 2009). Although several studies have shown the relationship of MD with schizophrenia (Altar et al. 2005, Ben-Shachar 2009, Mancuso et al. 2008), bipolar disorder (Andreazza et al. 2010, Cataldo et al. 2010, Sequeira et al. 2012), and major depressive disorder (MDD) (Gardner et al. 2003, Koene et al. 2009, Ryu et al. 2009), limited information is available on the relationship between MD and ADHD (Verma et al. 2016). The present study aims 
to investigate the relationship between ADHD and mtDNA copy number, one of the best biomarkers of MD, by comparing mtDNA copy number between the case and control groups, the relationship between mtDNA copy number and ADHD presentations and the association between mtDNA copy number and the severity of ADHD.

\section{SUBJECTS AND METHODS}

\section{Subjects}

This cross-sectional, and case-control study was conducted in accordance with the Helsinki Declaration and was ethically approved by the Clinical Research Ethics Committee of the Faculty of Medicine, Atatürk University No:B.30.2.ATA.0.01.00/56, Date:28/04/2016).

This cross-sectional, and case-control study was conducted in accordance with the Helsinki Declaration and was ethically approved by the Clinical Research Ethics Committee of the Faculty of Medicine, Atatürk University. Study participants were included on a voluntary basis after informing them and their families about the study and after obtaining written informed consent from the parents of participants who agreed to participate in the study.

The study included 112 children aged 6-16 years who were admitted to the Medical Faculty Research Hospital, Atatürk University, Erzurum, Turkey. Case group included 56 children diagnosed with ADHD for the first time who were admitted to the outpatient clinic of the Child and Adolescent Psychiatry Department, Medical Faculty Research Hospital, Atatürk University. Control group included 56 age- and sex-matched children without any previous history of or without active psychiatric disorders who visited the pediatric outpatient clinic of the Atatürk University Medical School.

\section{Methods}

Children diagnosed with ADHD based on clinical examination and semi-structured interview - Kiddie Schedule for Affective Disorders and Schizophrenia Present and Lifetime Version (K-SADS-PL) Turkish adaptation, according to Diagnostic and Statistical Manual of Mental Disorders (DSM-5) criteria who did not have any comorbid disorder, except oppositional and defiant disorder, and who did not receive any previous medication for ADHD were included in the case group. Children without any active psychiatric disorder according to K-SADS-PL and without any history of psychiatric disorder and treatment were included in the control group. Participants included in the case and control groups filled a sociodemographic data form prepared specifically for this study. The DSM-5-based clinical interviews were performed for determining ADHD Predominantly Inattentive, Predominantly Hyperactive-Impulsive among the children included in the case group. The parents and teachers of the case group were asked to rate their behavior according to Conners' rating scales to determine the severity of ADHD. All the participants were clinically evaluated and showed normal cognitive development based on the evaluation of their academic skills. Children with acute and/or chronic medical illnesses, major birth and delivery complications, history of trauma, and smoking habit were excluded from both the study groups.

The mtDNA copy number of each study participant was determined by performing real-time polymerase chain reaction (PCR). For this, $2 \mathrm{ml}$ venous blood sample was collected in an EDTA tube from each participant. Total genomic DNA was isolated from peripheral blood leukocytes using DNeasy Blood \& Tissue Kit (Qiagen, Hilden, Germany), according to the manufacturer's instructions, and concentration of the isolated DNA was determined using MaestroNano spectrophotometer (Maestrogen, Las Vegas, NV, USA).

MT-ND1 (mitochondrially encoded NADH dehydrogenase 1) (human) and HBB (hemoglobin subunit beta) (human) primers (Qiagen, Hilden, Germany) were used to calculate relative mtDNA copy number. PCR was performed in a $30-\mu \mathrm{L}$ reaction mixture containing $17.5 \mu \mathrm{L} 2 \times \mathrm{SYBR}$ Green Fluor qPCR master mix and $1 \mu \mathrm{L}$ of each primer. The concentration of primers were $10 \mu \mathrm{M}$. DNA concentration in each sample was adjusted to $20 \mathrm{ng} \cdot \mu \mathrm{L}^{-1}$, and $2 \mu \mathrm{L}$ DNA was added to each well. All case and controls run on the same plate at the same time with the same gene. Amplification was performed using Rotor-Gene-Q real-time PCR instrument by using the following conditions: initial denaturation at $95^{\circ} \mathrm{C}$ for 10 minutes, followed by 40 cycles of $94^{\circ} \mathrm{C}$ for 15 seconds and $60^{\circ} \mathrm{C}$ for 30 seconds. Melting curves for the primers showed specificity. Fluorescence emitted by the SYBR Green dye was recorded using the real-time PCR instrument, and $\mathrm{Ct}$ values of the initial concentration of each sample were calculated automatically by the PCR instrument during amplification. Acceptable standard deviation for $\mathrm{Ct}$ values was assumed to be 0.05 .

Sequences of primers used for determining mtDNA copy number are as follows: forward primer for the NADH dehydrogenase subunit 1 (ND1) gene on mtDNA, 5-TTAGTTGCTTGGTTGTGTATTCC-3; reverse primer for ND1 on mtDNA, 5-GAAAAAGGTAAAAAACTC TTTCAAGC-3; forward primer for the beta-globin $(H B B)$ gene on nuclear DNA (nDNA), 5-GGAGA TGCCTCAGAAACTGC-3; and reverse primer for $H B B$ on nDNA, 5-AGGTTGGAGGTCGG AAAGTT-3.

The number of cycles required for obtaining the threshold level of fluorescence signal is called "threshold cycle" or $\mathrm{Ct}$ value. $\Delta \mathrm{Ct}$ values of mtDNA and nDNA were calculated for each sample by using the PCR program. Difference between the $\triangle \mathrm{Ct}$ values of the mtDNA (NDI) and nDNA $(H B B)$ was calculated using the following formula: $\Delta \Delta \mathrm{Ct}=\mathrm{mtDNA} \mathrm{Ct}$ value nDNA Ct value. Relative mtDNA copy number was determined using the ratio of the amount of mtDNA to that of nDNA by using the following formula (Livak \& Schmittgen 2001), $2^{-\Delta \Delta \mathrm{Ct}}$. The $2^{-\Delta \Delta \mathrm{Ct}}$ method has been 
used in previous studies for assessing mtDNA copy number (Burch, Rhim \& Nyalwidhe 2016, McGarry et al. 2017, Perkins et al. 2016, Xu \& Li 2016).

\section{K-SADS-PL Turkish Adaptation}

Kauffman et al. developed the K-SADS-PL form according to DSM-3-R and DSM-4 diagnostic criteria for assessing the psychopathology of children and adolescents aged 6-18 years (Kaufman et al. 1997). The KSADS-PL is a semi-structured interview form whose validity and reliability in Turkish children and adolescents was determined by Gökler et al. (2004). The K-SADSPL form can be used to diagnose several psychiatric disorders, except special learning disorder, developmental disorders, and negative symptomatic schizophrenia.

\section{Conners' Parent Rating Scale}

Conners' Parent Rating Scale (CPRS-R:S) is a four-point Likert scale ( $0=$ never, $1=$ occasionally, 2 $=$ often, and $3=$ very often) that is used by parents. In the present study, the parents of the study participants were asked to rate the observed behavior of their children according to this scale. The scale includes inattention/cognitive problem, hyperactivity, ADHD index, and oppositional subscales. In the present study, subscale scores and total score were evaluated using a 27item short version of the CPRS-R:S (Kaner et al. 2013).

\section{Conners' Teacher Rating Scale}

Questions in Conners' Teacher Rating Scale (CTRS$\mathrm{R}: \mathrm{S})$ were answered by the teachers of the study participants according to the observed behaviors of the children in school. Like the CPRS, the CTRS is a fourpoint Likert scale. The CTRS includes inattention/cognitive problem, hyperactivity, ADHD index, and opositional subscales. In the present study, subscale scores and total score were evaluated using a 28 -item short form of the scale (Kaner et al. 2013).

\section{Statistical Analyses}

Statistical analyses were performed using Statistical Package for Social Sciences Statistics (SPSS) 23.0 program (SPSS Inc., Chicago, IL, USA). When alpha and beta errors were $5 \%$ and $20 \%$, respectively, the calculated power of the study was $89 \%$. Parametric and non-parametric statistical methods were used based on the distribution of data.

Difference in mtDNA copy number between the case and control groups was assessed using Student's $t$ test in independent groups. The Student's $t$-test and oneway ANOVA were used to investigate other differences among the case and control groups. Post hoc analysis (Tukey and Tamhane's T2 tests) was performed to compare multiple groups. Pearson's chi-square and Fisher exact tests were used to compare categorical variables.
Pearson's correlation analysis was used to evaluate the relationship between mtDNA copy number and numerical variables. Linear regression analysis was performed to exclude covariate factors that may affect mtDNA copy number for ADHD development. ROC analysis was performed to calculate the cutoff value of mtDNA copy number for ADHD diagnosis. A $p$ value of $<0.05$ was considered to be statistically significant.

\section{RESULTS}

\section{Demographic Data and Clinical Variables}

Of the included participants, $62.5 \%(n=70)$ were boys and $37.5 \%(n=40)$ were girls, with a mean age of $9.88 \pm 2.60$ years. Both the case and control groups included 56 children each. Classification of the children in the case group according to the DSM-5 ADHD presentations showed that 7 children $(12.5 \%)$ were predominantly inattentive, 4 children $(7.2 \%)$ were predominantly hyperactive-impulsive, and 45 children (80.3\%) were both inattentive and hyperactive-impulsive. Moreover, $19.6 \%(n=11)$ children showed comorbid oppositional defiant disorder (ODD).

Comparison of the sociodemographic characteristics of the children in the case and control groups showed that $64.3 \%(n=36)$ children with ADHD were boys and $35.7 \%(n=20)$ children with ADHD were girls. The male to female ratio was $1.8: 1$. In the control group, $60.7 \%(n=34)$ children were boys and $39.3 \%(n=22)$ children were girls. No significant difference was observed between the two groups with respect to sex $(p=0.696)$. The mean age of children in the case group was $9.80 \pm 2.42$ years and that of children in the control group was $9.96 \pm 2.78$ years, indicating no statistically significant difference between the two groups with respect to age $(p=0.745)$.

\section{Association Between mtDNA Copy Number and Demographic Characteristics of the Study Participants}

Amplification curves of the genes for calculating $\Delta \mathrm{Ct}$ values of the two groups are shown in Figures 1 and 2. The calculated mean $\Delta \mathrm{Ct}$ values of mtDNA $(N D 1)$ and nDNA $(H B B)$ for the case group were $11.98 \pm 0.59$ and $17.67 \pm 0.32$, respectively, and those for the control group were $12.44 \pm 0.84$ and $17.73 \pm 0.55$, respectively. The mean $\Delta \Delta \mathrm{Ct}$ value obtained by subtracting the $\Delta \mathrm{Ct}$ value of $\mathrm{nDNA}$ from that of mtDNA was $-5.70 \pm 0.71$ for the case group and $-5.29 \pm 0.80$ for the control group.

The mtDNA copy number was calculated for each study participant. No relationship and correlation was observed between mtDNA copy number and sex and age of the study participants $(p>0.05)$. Moreover, no statistically significant association was observed between mtDNA copy number and other sociodemographic characteristics of the study participants. 


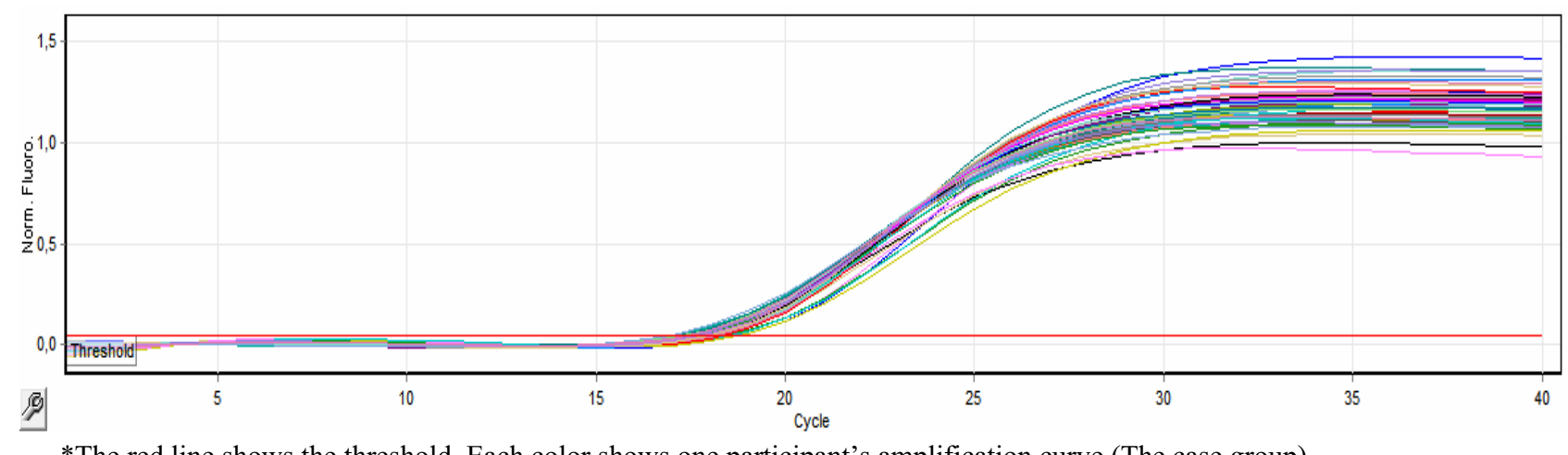

*The red line shows the threshold. Each color shows one participant's amplification curve (The case group)

Figure 1. Amplification Curves of the Cases Studied HBB Gene

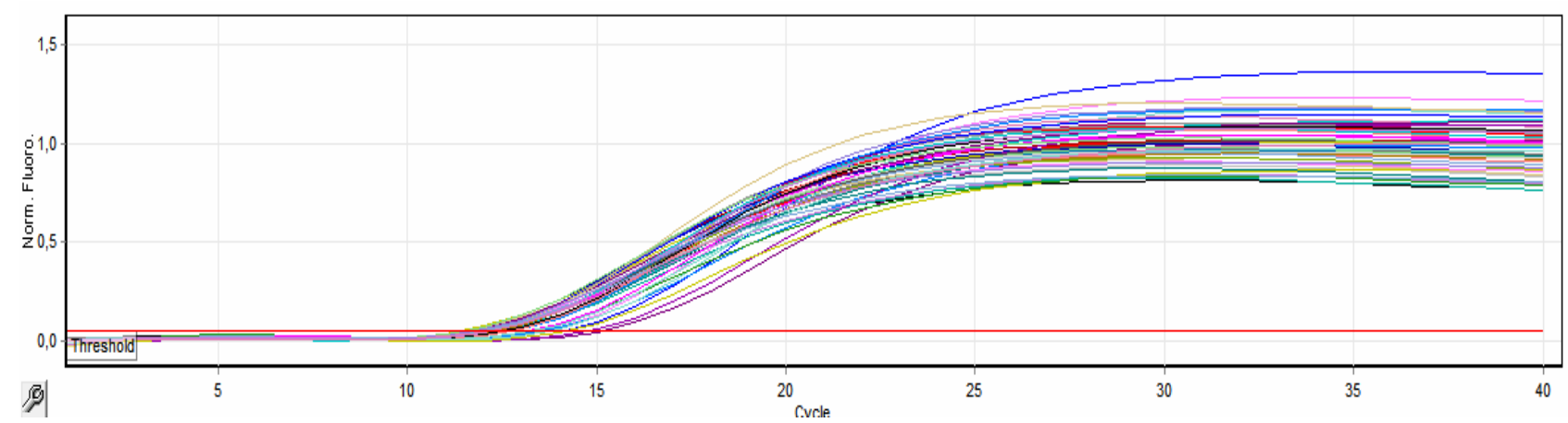

*The red line shows the threshold. Each color shows one participant's amplification curve (The control group)

Figure 2. Amplification Curves of the Controls Studied ND1 Gene

\section{Association Between mtDNA Copy Number and Clinical Variables}

The calculation of the mtDNA copy number of the children in the case and control groups showed that the mean mtDNA copy number of the children in the case group was $57.623 \pm 24.827$ and that of the children in the control group was $44.204 \pm 18.926$. This difference was statistically significant, indicating that mtDNA copy number of children with ADHD was significantly higher than that of normal healthy children $(p=0.002)$. The mean mtDNA copy number of the children in the case group was 1.30-times higher than that of the children in the control group (95\% confidence interval: 1.11-1.53).

Comparison of the children in the case group according to the ADHD presentation types showed that the mean mtDNA copy number of the children who were predominantly inattentive was $60.939 \pm 16.881$, that of the children who were both inattentive and hyperactive-impulsive was $58.558 \pm 26.368$, and that of the children who were predominantly hyperactiveimpulsive was $41.308 \pm 11.803$. However, no statistically significant difference was observed among the children showing different ADHD presentations $(p=0.391)$. Evaluation of comorbidities showed that the mean mtDNA copy number of children with comorbid ODD was $49.427 \pm 24.781$, whereas that of children without any comorbidity was $59.627 \pm 24.698$. However, this difference was not statistically signifi- cant $(p=0.225)$. Table 1 shows the distribution of mtDNA copy number according to the groups, ADHD presentations, and comorbidities. Assessment of the relationship between mtDNA copy number and CPRS and CTRS showed no significant correlation. In Figure 3 , this significant difference in the mtDNA copy number can be seen in the form of box-plot chart.

\section{Multiple Linear Regression and, ROC Curve}

Multiple regression analysis was performed to exclude confounding factors that affected mtDNA copy number. Factors that were significantly correlated with mtDNA copy number were added to the regression analysis. Results of the multiple regression analysis showed a significant correlation between mtDNA copy number and the study groups. Moreover, we found that mtDNA copy number was higher in the case group than the control group, and was not significantly correlated with other factors. Results of the multiple regression analysis of mtDNA copy number are given in Table 2.

ROC curve analysis was performed to calculate the cutoff value of mtDNA copy number in the two groups. The graph obtained from the ROC curve analysis is shown in Figure 4. Data obtained from the graph provided a $p$ value of 0.005 . Moreover, we observed that a cutoff value of 45 predicted the risks of ADHD development with $66 \%$ sensitivity and $59 \%$ specificity, with $\mathrm{p}<0.005$. 
Table 1. Distribution of mtDNA Copy Number by Groups, Presentations and Comorbidities

\begin{tabular}{|c|c|c|c|}
\hline & \multicolumn{3}{|c|}{ mtDNA Copy Number } \\
\hline & Mean & Standard Deviation & $\mathrm{p}$ \\
\hline Groups & & & $0.002^{\mathrm{a}}$ \\
\hline Case & 57.623 & 24.827 & \\
\hline Control & 44.204 & 18.926 & \\
\hline ADHD Presentations & & & $0.391^{\mathrm{b}}$ \\
\hline Combined & 58.558 & 26.368 & \\
\hline Predominantly Inattentive & 60.939 & 16.881 & \\
\hline Predominantly Hyperactive & 41.308 & 11.803 & \\
\hline Comorbidity & & & $0.225^{\mathrm{a}}$ \\
\hline Absent & 59.627 & 24.698 & \\
\hline ODD & 49.427 & 24.781 & \\
\hline
\end{tabular}

${ }^{\mathrm{a}}$ Student t-test, ${ }^{\mathrm{b}}$ One-way ANOVA

Table 2. Multiple Regression Model for mtDNA Copy Number

\begin{tabular}{|c|c|c|c|c|c|}
\hline \multirow{2}{*}{ Variables } & \multicolumn{2}{|c|}{ Nonstandard Coefficients } & \multirow{2}{*}{$\begin{array}{c}\text { Standard Coefficients } \\
\text { Beta }\end{array}$} & \multirow{2}{*}{$\mathrm{t}$} & \multirow{2}{*}{$\mathrm{p}$} \\
\hline & B & Standard Error & & & \\
\hline Constant & 54.874 & 20.344 & & 2.697 & 0.008 \\
\hline Groups & -15.450 & 4.360 & -0.338 & -3.544 & 0.001 \\
\hline Total Income of Family & -4.649 & 2.507 & -0.174 & -1.855 & 0.066 \\
\hline Physical Illness of Mother & 11.854 & 7.347 & 0.148 & 1.613 & 0.110 \\
\hline Smoking of Mother & -2.459 & 6.192 & -0.038 & -0.397 & 0.692 \\
\hline Smoking of Father & 2.025 & 4.461 & 0.044 & 0.454 & 0.651 \\
\hline Medical Problems at Birth & 4.674 & 4.835 & 0.095 & 0.967 & 0.336 \\
\hline
\end{tabular}

*Regression Model $\mathrm{R}^{2}=0.14$

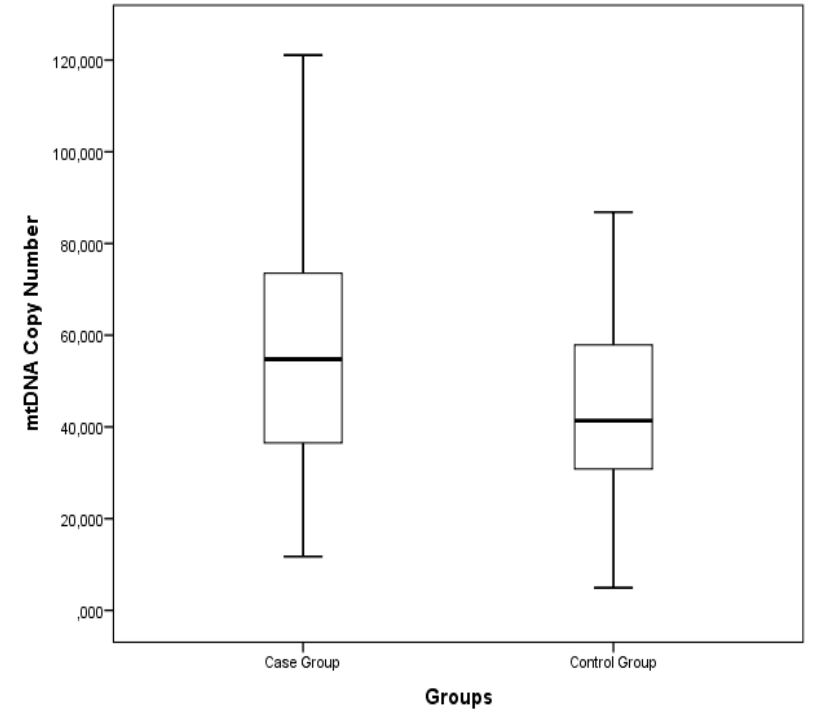

*In this box plot graph, significant mtDNA copy number difference can be seen between groups

Figure 3. The mtDNA Copy Numbers of Groups

\section{DISCUSSION}

We observed that the mean mtDNA copy number of the children in the case group was significantly higher (by 1.3 times) than that of the children in the control group. To the best of our knowledge, this is the first study to examine the relationship between ADHD and mtDNA copy number. Analysis of patients from Childhood Autism Risk from Genes and Environment

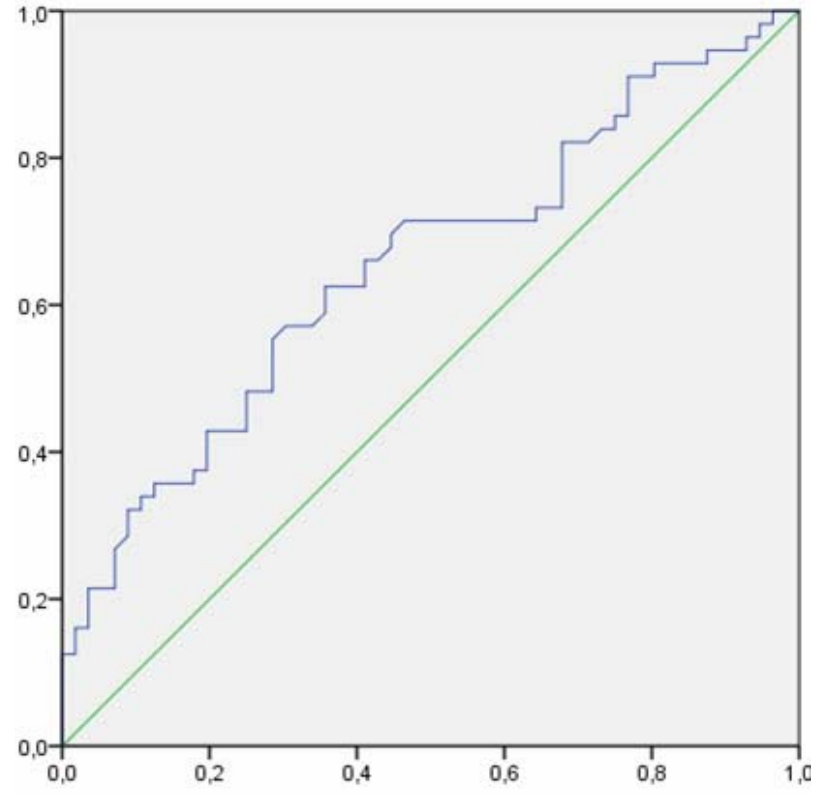

Figure 4. ROC Curve of mtDNA Copy Number

(CHARGE) study showed that the mtDNA copy number of children with ASD was 1.4-times higher than that of normally developing children; however, this difference was not statistically significant. Moreover, this study showed that the incidence of mtDNA deletions was 2.6-times higher in children with ASD than in normally developing children (Wong et al. 2016). Another case report of patients from the CHARGE study showed that the mtDNA copy number of children 
with autism spectrum disorder (ASD) was 1.5-times higher than that of healthy children (Napoli et al. 2014). In the present study, the mtDNA copy number of children with ADHD was 1.3-times higher than that of normal children, which was similar to that observed for children with ASD. Similar to autism researches, higher mtDNA copy number in ADHD group may suggest mitochondrial dysfunction in the etiopathogenesis of ADHD (Bai et al. 2004).

Although there are a number of factors such as changes in mitochondrial biogenesis, mitochondrial DNA replication machinery, mitophagy that may cause mtDNA copy number change, mtDNA copy number may be an indicator of MD (Clay Montier et al. 2009, Malik \& Czajka 2013, Malik et al. 2011). Only a few studies have assessed the role of MD in ADHD development. A recent study by Verma et al. compared the activities of cytoplasmic hybrid neuroblastoma cells (called cybrid cells) generated by placing platelets from patients with ADHD and control subjects with neuroblastoma cells lacking mitochondria (Verma et al. 2016). Results of this study showed that ATPase 6/8 transcription level, mitochondrial complex $\mathrm{V}$ activity, cellular and mitochondrial respiration, and mitochondrial membrane potential were lower and oxidative stress was higher in cybrid neuronal cells prepared from the platelets of patients with ADHD than in those prepared from the platelets of control subjects. Thus, the result of this study suggested that mitochondrial pathology is a risk factor of ADHD (Verma et al. 2016), thus supporting the role of MD in ADHD development.

Many studies have investigated changes in the mtDNA copy number of patients with psychiatric disorders. Some studies have reported higher mtDNA copy number in the peripheral lymphocytes and postmortem brain tissues of patients with ASD than in those of control subjects (Chen et al. 2015, Gu et al. 2013). Chen et al. suggested that increased mtDNA copy number was associated with increased replication and decreased degradation of mtDNA because of acute oxidative stress response (Chen et al. 2015). Similarly, Cai et al. reported that the mtDNA copy number of patients with MDD was higher than that of control subjects (Cai et al. 2015). However, they also suggested that the change in the mtDNA copy number affected intercellular communication between hypothalamo-pituitary axis and corticosteroid pathways, leading to MDD development.

Several hypotheses have been proposed to explain the association between MD and psychopathology. The first hypothesis is the direct damage of mtDNA caused by increased oxidative stress, which results in MD. Oxidative stress disrupts protein and chromatin structures by breaking down lipids, proteins, and nucleic acids and by disrupting membrane lipid integrity, thus inducing $\mathrm{MD}$, and apoptosis, and eventually psychopathologies (Avery 2011, García-Giménez et al. 2012, Martínez et al. 2010, Wang, Yang \& Yi 2012). The second hypothesis is the effect of oxidative stress on mitochondrial energy production. ADP and $\mathrm{H}_{2} \mathrm{O}$ are produced from
ATP during intense energy production in the mitochondria of neurons. Neurons are extremely sensitive to oxidative stress. Studies suggest that neurons of patients with psychiatric disorders are more vulnerable to MD, ROS (e.g., superoxide anions and hydrogen peroxide that cannot be eliminated appropriately), and environmental stimuli (Davies 1995, DiMauro \& Schon 2008, Mattson \& Liu 2002, Rich 2003).

Although the power value of the sample size in the present study was sufficient to represent all ADHD cases, the sample size was not sufficient to compare among the different ADHD presentation types. A general limitation of mtDNA studies involving peripheral blood samples rather than brain tissue samples also applies to the present study. Moreover, we could not conduct a next-generation sequencing analysis for a more detailed examination and detection mtDNA deletions because of the high cost associated with this genetic test.

\section{CONCLUSIONS}

The results of the present study showed that increased mtDNA copy number was significantly correlated with ADHD development, indicating that MD may contribute to the etiopathogenesis of ADHD. However, the high mtDNA copy number detected in patients with ADHD should be validated using different tissue samples. Moreover, follow-up studies should be performed using postmortem brain tissues. In addition, studies involving whole-exome sequencing should be performed to re-evaluate the relationship between MD and ADHD to understand the etiology of this disorder.

\section{Acknowledgements:}

This work was supported by Research Fund of the Ataturk University. Project Number: TTU-2017-6059.

Conflict of interest: None to declare.

\section{Contribution of individual authors:}

Design of the study: Hakan Öğütlü \& Onur Burak Dursun.

Literature search and data collection: Hakan Öğütlü.

Analysis: Haktan Bağış Erdem \& Abdülgani Tatar.

Statistical Analyses: İbrahim Selçuk Esin \& Hakan Öğütlü.

Interpretation of data: Onur Burak Dursun \& Hakan Öğütlü.

Manuscript writing: Hakan Öğütlü.

Supervision: Onur Burak Dursun \& Ibrahim Selçuk Esin.

\section{References}

1. Altar CA, Jurata LW, Charles V, Lemire A, Liu P, Bukhman $Y$ et al.: Deficient hippocampal neuron expression of proteasome, ubiquitin, and mitochondrial genes in multiple schizophrenia cohorts. Biol Psychiatry 2005; 58:85-96 
2. Andreazza AC, Shao L, Wang J-F, Young LT: Mitochondrial complex I activity and oxidative damage to mitochondrial proteins in the prefrontal cortex of patients with bipolar disorder. Arch Gen Psychiatry 2010; 67:360-368

3. APA (American Psychiatric Association): Diagnostic and Statistical Manual of Mental Disorders (DSM-5), 2013

4. Archana E, Pai P, Prabhu BK, Shenoy RP, Prabhu K, Rao A: Altered biochemical parameters in saliva of pediatric attention deficit hyperactivity disorder. Neurochem Res 2012; 37:330-334

5. Avery SV: Molecular targets of oxidative stress. Biochem $J$ 2011; 434:201-210

6. Bai R-K, Perng C-L, Hsu C-H, Wong L-JC: Quantitative PCR Analysis of Mitochondrial DNA Content in Patients with Mitochondrial Disease. Ann N Y Acad Sci 2004; 1011:304-309

7. Ben-Shachar D: The interplay between mitochondrial complex I, dopamine and Sp1 in schizophrenia. J Neural Transm 2009; 116:1383-1396

8. Burch TC, Rhim JS, Nyalwidhe JO: Mitochondria Biogenesis and Bioenergetics Gene Profiles in Isogenic Prostate Cells with Different Malignant Phenotypes. Biomed Res Int 2016; 2016:1785201

9. Burçak G, Andican G: Oksidatif DNA Hasari ve Yașlanma. Cerrahpaşa Tip Dergisi 2004; 35

10. Cai N, Chang S, Li Y, Li Q, Hu J, Liang J et al.: Molecular signatures of major depression. Curr Biol 2015, 25:1146-1156

11. Cataldo AM, McPhie DL, Lange NT, Punzell S, Elmiligy $S$, Nancy $Z Y$ et al.: Abnormalities in mitochondrial structure in cells from patients with bipolar disorder. Am J Pathol 2010; 177:575-585

12. Ceylan M, Sener S, Bayraktar AC, Kavutcu M: Oxidative imbalance in child and adolescent patients with attentiondeficit/hyperactivity disorder. Prog Neuropsychopharmacol Biol Psychiatry 2010; 34:1491-1494

13. Ceylan MF, Sener S, Bayraktar AC, Kavutcu M: Changes in oxidative stress and cellular immunity serum markers in attention-deficit-hyperactivity disorder. Psychiatry Clin Neurosci 2012; 66:220-226

14. Chen S, Li Z, He Y, Zhang F, Li H, Liao Y et al.: Elevated mitochondrial DNA copy number in peripheral blood cells is associated with childhood autism. BMC Psychiatry 2015; 15:50

15. Clay Montier LL, Deng J, Bai Y: Number matters: control of mammalian mitochondrial DNA copy number. J Genet Genomics 2009; 36:125-131

16. Davies KJ: Oxidative stress: the paradox of aerobic life. Biochem Soc Symp Portland Press Limited 1995; 61:1-31

17. DiMauro S, Schon EA: Mitochondrial disorders in the nervous system. Annu Rev Neurosci 2008; 31:91-123

18. Eşrefoğlu M: Cell injury and death: Oxidative stress and antioxidant defense system. Turkiye Klinikleri Journal of Medical Sciences 2009; 29:1660-1676

19. Filomeni G, Ciriolo MR: Redox control of apoptosis: an update. Antioxid Redox Signal 2006; 8:2187-2192

20. Garcia-Giménez JL, Ledesma AMV, Esmoris I, RomáMateo C, Sanz P, Viña J et al.: Histone carbonylation occurs in proliferating cells. Free Radic Biol Med 2012; 52:1453-1464

21. Gardner A, Johansson A, Wibom R, Nennesmo I, von Döbeln U, Hagenfeldt L et al.: Alterations of mitochondrial function and correlations with personality traits in selected major depressive disorder patients. $J$ Affect Disord 2003; 76:55-68

22. Gökler B, Ünal F, Pehlivantürk B, Kültür EÇ, Akdemir D, Taner Y: Reliability and validity of schedule for affective disorders and schizophrenia for school age childrenpresent and lifetime version-Turkish version (K-SADS-PLT). Turkish Journal of Child and Adolescent Mental Health 2004: 11:109-116

23. Gu F, Chauhan V, Kaur K, Brown W, LaFauci G, Wegiel $J$, et al.: Alterations in mitochondrial DNA copy number and the activities of electron transport chain complexes and pyruvate dehydrogenase in the frontal cortex from subjects with autism. Transl Psychiatry 2013; 3:e299

24. Kaner S, Buyukozturk S, Iseri E: Conners parent rating scale-revised short: Turkish standardization study/Conners anababa dereceleme olcegi-yenilenmis kisa: Turkiye stardardizasyon calismasi. Noro Psikiyatr Ars 2013; 50:100-110

25. Kaner S, Büyüköztürk S, Iseri E: Conners Ögretmen Dereceleme Ölçegi-Yenilenmis Kisa: Türkiye Uyarlama Çalismasi. Egitim ve Bilim 2013; 38:81

26. Kaufman J, Birmaher B, Brent D, Rao UMA, Flynn C, Moreci P, Williamson D, Ryan N: Schedule for affective disorders and schizophrenia for school-age children-present and lifetime version (K-SADS-PL): initial reliability and validity data. J Am Acad Child Adolesc Psychiatry 1997; 36:980-988

27. Kim GH, Kim JE, Rhie SJ, Yoon S: The role of oxidative stress in neurodegenerative diseases. Exp Neurobiol 2015; 24:325-340

28. Koene S, Kozicz T, Rodenburg R, Verhaak C, De Vries $M$, Wortmann $S$ et al.: Major depression in adolescent children consecutively diagnosed with mitochondrial disorder. $J$ Affect Disord 2009; 114:327-332

29. Livak KJ, Schmittgen TD: Analysis of relative gene expression data using real-time quantitative $P C R$ and the 2-CT method. Methods 2001; 25:402-408

30. Malik AN, Czajka A: Is mitochondrial DNA content a potential biomarker of mitochondrial dysfunction? Mitochondrion 2013; 13:481-492

31. Malik AN, Shahni R, Rodriguez-de-Ledesma A, Laftah A, Cunningham P: Mitochondrial DNA as a non-invasive biomarker: accurate quantification using real time quantitative PCR without co-amplification of pseudogenes and dilution bias. Biochem Biophys Res Commun 2011; 412:1-7

32. Mancuso M, Ricci G, Choub A, Filosto M, DiMauro S, Davidzon $G$ et al.: Autosomal dominant psychiatric disorders and mitochondrial DNA multiple deletions: report of a family. J Affect Disord 2008; 106:173-177

33. Martínez A, Portero-Otin M, Pamplona R, Ferrer I: Protein targets of oxidative damage in human neurodegenerative diseases with abnormal protein aggregates. Brain Pathol 2010; 20:281-297

34. Mattson MP, Liu D: Energetics and oxidative stress in synaptic plasticity and neurodegenerative disorders. Neuromolecular Med 2002; 2:215-231

35. McGarry T, Biniecka M, Gao W, Cluxton D, Canavan M, Wade $S$ et al.: Resolution of TLR2-induced inflammation through manipulation of metabolic pathways in rheumatoid arthritis. Sci Rep 2017; 7:43165

36. Napoli E, Wong S, Hertz-Picciotto I, Giulivi C: Deficits in bioenergetics and impaired immune response in 
granulocytes from children with autism. Pediatrics 2014; 133:e1405-1410

37. Perkins M, Wolf AB, Chavira B, Shonebarger D, Meckel J, Leung $L$ et al.: Altered energy metabolism pathways in the posterior cingulate in young adult apolipoprotein E4 carriers. J Alzheimers Dis 2016; 53:95-106

38. Polanczyk G, de Lima MS, Horta BL, Biederman J, Rohde LA: The worldwide prevalence of ADHD: a systematic review and metaregression analysis. Am J Psychiatry 2007

39. Rich P: The molecular machinery of Keilin's respiratory chain: Portland Press Limited, 2003

40. Ryu JS, Lee SJ, Sung IY, Ko TS, Yoo HI: Depressive episode with catatonic features in a case of mitochondrial myopathy, encephalopathy, lactic acidosis, and stroke-like episodes (MELAS). J Child Neurol 2009; 24:1307-1309

41. Selek S, Bulut M, Ocak AR, Kalenderoğlu A, Savaş HA. Evaluation of total oxidative status in adult attention deficit hyperactivity disorder and its diagnostic implications. J Psychiatr Res 2012; 46:451-455
42. Sequeira A, Martin MV, Rollins B, Moon EA, Bunney WE, Macciardi F, et al.: Mitochondrial mutations and polymorphisms in psychiatric disorders. Front Genet 2012; 3

43. Valko M, Rhodes C, Moncol J, Izakovic M, Mazur M: Free radicals, metals and antioxidants in oxidative stress-induced cancer. Chem Biol Interact 2006; 160:1-40

44. Verma P, Singh A, Nthenge-Ngumbau DN, Rajamma U, Sinha $S$, Mukhopadhyay $K$ et al.: Attention deficit-hyperactivity disorder suffers from mitochondrial dysfunction. BBA clinical 2016; 6:153-158

45. Wang Y, Yang J, Yi J: Redox sensing by proteins: oxidative modifications on cysteines and the consequent events. Antioxid Redox Signal 2012; 16:649-657

46. Wong S, Napoli E, Krakowiak P, Tassone F, HertzPicciotto I, Giulivi C: Role of p53, mitochondrial DNA deletions, and paternal age in autism: a case-control study. Pediatrics 2016; e20151888

47. Xu G, Li JY: ATP5A1 and ATP5B are highly expressed in glioblastoma tumor cells and endothelial cells of microvascular proliferation. J Neurooncol 2016; 126:405-413

Correspondence:

Hakan Öğ̈̈tlü, MD

Ankara City Hospital, Department of Child and Adolescent Psychiatry

06000 Ankara, Turkey

E-mail:hogutlu@gmail.com 